$2 \cdot 47 \mathrm{~A}$. between square faces (observed value $2 \cdot 53 \mathrm{~A}$.) and a bond angle of $75^{\circ}$.

Further analysis of the structure is now in progress and the results will be published in detail elsewhere.

Laboratory for General and

D. GRDENIĆ

Inorganic Chemistry,

Faculty of Science,

University of Zagreb,

Department for Structural and

B. Matković

Inorganic Chemistry,

Rudjer Bošković Institute,

54 Bijenička c.,

Zagreb, Yugoslavia. June 11.

${ }^{2}$ O'Brien, Th. D., in "The Chemistry of the Coordination Compourds", edit. by J. C. Bailar, jun., 394 (Reinhold, New York, 1956).

${ }^{2}$ Katz, J. J., and Seaborg, G. T., "The Chemistry of the Actinide El ments", 463 (Methuen, London, 1957).

${ }^{3}$ Grdenic, D., and Matkovic, B., Croat. Chem. Acta, 30, 95 (1959).

\section{Absorbents for Aldehydes and Olefins}

THE usual forms of absorbents for aldehydes, such as ammonia and bisulphite solutions, cannot readily be used in vacuum systems because they are liquid and volatile. A very convenient absorbent may be made by suspending on 25-52 mesh powdered firebrick ('Fossalsil') 25 per cent by weight of a mull of sodium bisulphite in ethylene glycol. We have repeatedly used this powder packed in $10 \mathrm{~cm}$. of a $15 \mathrm{~mm}$. internal diameter tube to absorb the butyraldehyde remaining in a mixture after a photolysis. Subsequent analysis of the reaction products indicates that less than $0 \cdot 3$ umole out of the initial $500 \mu$ moles remains unabsorbed after the vapour has been passed three times through the packed tube. Acetone is not similarly absorbed.

An excellent absorbent for olefins may similarly be made from a mixture of $9 \mathrm{gm}$. mercuric acetate, $3 \mathrm{gm}$. mercuric nitrate and $20 \mathrm{gm}$. ethylene glycol on $100 \mathrm{gm}$. of firebrick.

This research was supported by a grant from the Petroleum Research Fund administered by the American Chemical Society. Grateful acknowledgment is made to the donors.

$$
\text { J. A. KERR }
$$

A. F. Trotman-DrChenson

Chemistry Department,

The University,

Edinburgh 9.

June 12

\section{Formation of a Transition Metal-Hydrogen Bond in Aqueous Solution}

There are several known transitional metal complex systems which are concerned with either the absorption or evolution of molecular hydrogen, and some of them, for example the copper acetate in quinoline system, can function as hydrogentransfer systems ${ }^{1-3}$. It has been suggested by many workers in the past that complexes containing hydrogen bonded to a transitional metal are involved in these systems, but direct proof for the existence of such bonds has been lacking.

A sufficient number of complex compounds containing metal-hydrogen bonds has now been studied by high-resolution nuclear magnetic resonance methods to permit the specific characterization by this technique of a proton bound to a transitional metal. Thus the compounds $\left(\mathrm{C}_{5} \mathrm{H}_{5}\right)_{2} \mathrm{ReH}, \quad\left(\mathrm{C}_{5} \mathrm{H}_{5}\right)_{2} \mathrm{ReH}_{2}{ }^{+}$ (ref. 4), $\mathrm{HCo}(\mathrm{CO})_{4}$ (ref. 5), $\mathrm{H}_{2} \mathrm{Fe}(\mathrm{CO})_{4}$ (ref. 6), $\mathrm{HMn}(\mathrm{CO})_{4}$ (ref. 7), $\mathrm{HM}(\mathrm{CO})_{3}\left(\mathrm{C}_{5} \mathrm{H}_{5}\right)[M=\mathrm{Cr}$, Mo, W] (ref. 8), $\mathrm{HPtCl}\left(\mathrm{PR}_{3}\right)_{2}$ (ref. 9), and $\left(\mathrm{C}_{3} \mathrm{H}_{5}\right)_{2} \mathrm{MH}_{2}$ $[M=$ Mo, W] (ref. 7) have all been shown to have proton resonances shifted to $450-800$ cycles/sec. (at $40 \mathrm{Mc} . / \mathrm{s}$.) relative to water, on the high field side.

During the course of studies of such compounds and related systems we have examined the cobaltous cyanide-potassium cyanide system, which has been rather carefully studied by Winfield and others ${ }^{1210}$. In aqueous solutions a proton resonance at a position characteristic for a proton bound to the metal atom has been detected, at $698+2$ cycles/sec. (at $40 \mathrm{Mc} . / \mathrm{s}$.) relative to water. The resonance is not observed at cyanide/cobalt ratios less than $3 \cdot 5$, and it is not affected by excess cyanide up to a cyanide/ cobalt ratio of $8 \cdot 0$. The presence of an atmosphere of hydrogen above the solution is not necessary for the appearance of this resonance line, so that the proton bound to the metal is clearly derived from water. The rest of the water molecule, either as free $\mathrm{OH}$ radicals or as oxygen, presumably oxidizes the aquo cobaltous cyanide compl: $x$. The proton resonance disappears on admission of oxygen and other oxidizing agents to the solution. While there is, as yet, no specific information concerning the nature of the hydrogenated species, it seems reasonable to postulate that it is the $\left[\mathrm{HCo}(\mathrm{CN})_{4}\right]=$ ion. The large chemical shift of the proton resonance shows that the proton in such a species is exchanging with water in the aqueous alkaline solution only very slowly, and the average chemical life-time of the proton on the metal atom must be greater than about $10^{-4}$ sec.

These studies will be more fully described elsewhere.

$$
\begin{aligned}
& \text { W. P. Griffith } \\
& \text { L. Pratt } \\
& \text { G. Wilkinson }
\end{aligned}
$$

Inorganic Chemistry Research Laboratories,

Imperial College of Science and Technology,

London, S.W.7.

June 20.

${ }^{1}$ For reviews and references, see: Halpern. J., Quart. Rev., 10, 463 (1956): Winfield, M. E., A ustr. J. Sci. Res., A4, 385 (1951).

'Baston, J., Kelso King, N., and Winfield, M. W., "Advances in Catalysis", 9, 312 (Academic Press, New York, 1957).

"Wender, I., and Sternberg, H. W., "Advances in Catalysis", 594 (Academic Press, New York, 1957).

${ }^{4}$ Birmingham, J. M., and Wilkinson, G., J. Amer. Chem. Soc., 77, 3421 (1955).

${ }^{5}$ Friedel, R. A., Wender, I., Shufter, S. L., and Sternberg, H. W. J. Amer. Chem. Soc., 7r, 3951 (1955).

${ }^{6}$ Cotton, F. A., and Wilkinson, G., Chem and Indust, 1305 (1956).

'Down, J., Green, M. I. H., and Wilkinson, G. (unpublished work).

- Piper, T. S., and Wilkinson, G., J. Inorg. Nucl. Chem., 3, 104 (1956).

${ }^{8}$ Chatt, J., Duneanson, L. A., and Shaw, B. L., Proc. Chem. Soc. $343(1957)$.

${ }^{10}$ Kelso King, N., and Winfield, M. E., J. Amer. Chem. Soc., 80, 2060 (1958).

\section{A Radiocarbon Profile in the Tasman Sea}

DURING recent hydrological investigations in the eastern Tasman Sea by the New Zealand Oceano. graphic Institute a series of sea-water samples was collected for carbon-14 analysis as mentioned recently by Rafter and Fergusson'.

The sampling position (New Zealand Oceanographic Institute Station A344) was in approximately latitude $37^{\circ} 25^{\prime} \mathrm{S}$. ; longitude $170^{\circ} 35^{\prime} \mathrm{E}$. over 